40-inch Yerkes refractor. No other scale gauge could be more striking to me, as I recall so vividly the arrival of the 40 -inch objective at the Yerkes Observatory in 1897. Contrasted with our previous refractors, it greatly excited our anticipations, and our hopes of good performance have not been disappointed during the intervening years."
The accompanying illustrations show (Fig. 1) a tentative sketch of the complete 200 -inch reflecting telescope, and (Fig. 2) Dr. McCauley testing the great disk with polarised light at the Corning glass works. The design shown in Fig. 1 may be altered in several respects before construction takes place.

\title{
British Chemical Plant Exhibition
}

$\mathrm{O}^{\mathrm{N}}$ Monday next, June 22, the Right Hon. J. Ramsay Macdonald is to open an exhibition of British Chemical Plant at the Central Hall, Westminster, S.W.1. This exhibition, which has been organised by the British Chemical Plant Manufacturers' Association, will occupy the ground floor and basement of the Central Hall, and will run concurrently with the Chemical Engineering Congress of the World Power Conference, which is meeting in the same building from 9.30 a.m. until 6.30 p.m. on June $22-27$ and until 8 p.m. on June 23 and 26.

Although the British Chemical Plant Manufacturers' Association has sponsored this exhibition, the management committee has wisely given firms not members of the Association an opportunity of displaying their manufactures. One condition, however, has been imposed on all exhibitors, namely, that all plant exhibited shall be of British manufacture, the criterion laid down being that at least 75 per cent of the cost of the plant shall represent labour or material within Great Britain or the Empire.

The last exhibition organised by this Association was held in 1931, so that those who are attending this, the first international conference on chemical engineering, may be able to observe the rapid progress made within five years. To others who are not intimately acquainted with chemical engineering, the exhibition should provide an admirable illustration of the scope of the subject and the complexity of the plants which may have to be used when a laboratory experiment or research has to be developed into an industrial process.

Of the forty-eight firms which are exhibiting, thirty have declared that a number of exhibits which they are showing, amounting to a hundred in all, have not been shown by them at any previous British chemical plant exhibition.

Materials of construction being of outstanding importance to the chemical engineer, it is not surprising to find that this aspect of the subject has received considerable attention, both from the research associations working in close alliance with the Department of Scientific and Industrial Research, as well as commercial enterprises. Numerous exhibits are therefore to be found throughout the stands of the exhibition which deal with the improvements in the cast irons now available, developments which have taken place in steels designed to resist corrosion or withstand high temperatures, the protection of steel by glass, enamels, or other metals.

Owing, for example, to the tendency to intergranular corrosions in austenitic stainless steels, after they have been heated to a dull red heat, the welding of such steels into chemical plant having dimensions greater than the internal dimensions of the heat treatment furnace could only be done at the expense of the corrosive resistance properties of the welds. Research in this field, however, has shown that the addition of silicon to such a chromium nickel steel not only eliminates the necessity for the heat treatment of the welded joints, thus removing the limitations to the size of vessel which could be manufactured and still retain its resistant qualities, but also that this type of steel increases the resistance to attack by various acids, and oxidation at high tempera. tures. Examples of vessels made from this type of steel as well as various types of welding and cutting equipment are on view in the industrial section of the exhibition.

Research has not been idle in connexion with the non-ferrous metals and their alloys, whilst a considerable amount of development has also taken place in refractory and ceramic materials, possibly accelerated by the extended use of metals or alloys possessing high corrosive resisting properties. Here again is ample illustration of the progress which has been effected by the typical pieces of chemical plant to be seen on the various stands in the exhibition.

The National Physical Laboratory and kindred associations have been interested in the problem 
of heat transmission, the properties of steels when at a high temperature and the behaviour of steels in the presence of superheated steam, some or all of which have a direct bearing on the design of high-pressure autoclaves, forced circulation evaporators, rotary economisers, heat exchangers, high vacuum distillation plants, band and drum dryers. Many pieces of apparatus of this character are to be found on various stands.

Still taking the exhibit organised by the Department of Scientific and Industrial Research, which will be found in a separate room in the north-east corner of the ground floor, as the key to the exhibition, it will be found that there is a number of exhibits which illustrate the work being carried on at the Fuel Research Station in connexion with the coal survey, carbonisation of coal, pulverisation of fuel and hydrogenation-cracking of tar, and on passing into the industrial section, models can be seen of a carburetted water-gas plant and a waterless gas holder, as well as a small coal water-gas plant and appliances for using gas such as burners, gas-fired boiler and oil heaters. The pulverisation of coal naturally directs attention to the size-reduction machinery on view on several of the stands, but as crushing and grinding machines in industry usually have large outputs and therefore are of large size, models in some instances have been installed to illustrate the type and action of the firm's make of machine. After size-reduction has been completed, the broken pieces are usually separated either according to size or composition, and again the visitor will note on several stands screening devices of the latest types.

Where the problem facing the chemical engineer is to obtain hydrogen in a pure state suitable for hydrogenation processes, a visit to the exhibition will show him some of the latest developments in the cells used in the electrolytic production of hydrogen and oxygen from water. The juxtaposition of this stand and the welding stand serves to remind the visitor that the oxygen produced by the electrolysis need not as formerly constitute an industrial waste, but may be readily used as one of his raw materials by the welder.

Since the problem of separation arises in mix. tures where the components forming the mixture can exist in the same or different states of matter, the types of plant designed for separation problems are very varied. In the exhibition are numerous examples of equipment intended for the separation of mixtures of solids and liquids, such as filters and filter parts ranging from the sterilising type where the solid content is extremely small to the various types designed to separate thick slurries, centrifugal machines, classifiers, flocculators and thickeners. Industrially, many of these machines are of considerable size and would therefore be too large for exhibition purposes, but the firms desirous of making a representative display have in such cases provided small-scale equipment, models, spare parts or other means of illustrating the types of plants they supply and their operation.

The converse problem, namely, mixing solid with solid, or solid with liquid, or liquid with liquid, is of equal importance in the chemical industry, and on various stands throughout the exhibition a variety of types of plant which have been developed for this purpose can be studied.

An important problem in chemical works is often the movement of large quantities of material, for the chemical engineer has not only to consider the physical and chemical properties of the substance to be moved but also, as in all other operations, the efficiency with which it is carried out, so that the cost of the final product may not be unduly raised. It is, therefore, not surprising that on many stands in this exhibition will be found examples of pumps, valves, pipe-lines and so on, many of which have been specially designed and constructed for use in factories where corrosive liquids or liquids containing large percentages of solid matter have to be transported. On the other hand, the aim of the designer has sometimes been to produce a reliable machine suitable for the food industry, where no form of contamination by lubricants or other means can be tolerated.

Efficiency being the watch-word in modern industry, it is pleasing to observe that in the present exhibition this factor has not been over. looked, but that there is on view apparatus for measuring temperature, pressure, humidity, controllers and recorders, various types of meters for the measurement of air and gas, steam and liquids as well as recorders for $p \mathrm{H}$ values and such checks as ean be made by colour comparisons.

Moving about in the industrial section, one sees how closely the work of the various research associations is being studied and followed by the plant manufacturer.

The Chemical Works Regulations of 1922 contain rules relating to the equipment to be provided and used by anyone entering a chamber containing poisonous material and so on, and even this section of the equipment of a chemical factory is well represented at the exhibition. Another group of stands of interest to those concerned with chemistry, chemical engineering or chemical industry contains the literature available, both books and periodicals.

There is much of interest in the exhibition to everyone associated with chemical industry, so that it seems a pity that members attending the Congress will only be able to visit the exhibition during intervals between the meetings upstairs. 